\title{
DIAGNOSIS KESULITAN BELAJAR MATA KULIAH BAHASA PALI PADA MAHASISWA STABN SRIWIJAYA TANGERANG BANTEN
}

\author{
Iin Suwarni \\ Sekolah Tinggi Agama Buddha Negeri Sriwijaya Tangerang Banten \\ iin.suwarni@yahoo.co.id
}

\begin{abstract}
The learning process is expected to change for those who do the learning. In addition to changes in knowledge and behavioral changes include skills, habits, attitudes, understandings, awards, interests, adjustments, and others from learners. Learning process is not always smooth, many obstacles encountered. Based on the observations, when students are given an explanation and given a matter of practice, can do well. But at the time of the assessment, the students found it difficult. This can be seen from the assessment results are less satisfactory. So the purpose of this study is to describe the difficulties of learning Pali Language courses at students STABN Sriwijaya Tangerang Banten. This research is quantitative descriptive. Subject of this research is student of STABN Sriwijaya Tangerang Banten. Technique of collecting data by way of questioner. Quantitative data analysis from this research using percentage model. The results of this study indicate that the difficulty of studying Pali Language in Student STABN Sriwijaya Tangerang Banten seen from the language aspect of most students get a moderate score of $71.42 \%$, meaning that this group has a diagnosis of learning difficulties in the level of medium to the Pali language. The percentage of students who get high score is only $14.29 \%$ and students who have low score of $14.29 \%$. This means that groups of students who have a diagnosis of learning difficulties are high and low to the Pali Language courses get the same percentage of $14.29 \%$. From the description of the diagnosis of learning difficulties of internal factors, it is known that the greatest score of the students get the average score of $76 \%$, meaning that this group has the dimension of internal learning difficulty diagnosis in the medium level to the Pali language. While from the description of the diagnosis of learning difficulties external factors, known acquisition value that the greatest part of the students get a moderate score of $71.43 \%$, meaning that this group has a dimension of the diagnosis of learning difficulties external factors in the medium level of Pali Language courses.
\end{abstract}

Keywords: Learning Difficulties, Pali Language

\section{A. Pendahuluan}

Belajar membawa perubahan bagi yang melakukan belajar. Perubahan tingkah laku bukan hanya menyangkut pengetahuan saja akan tetapi lebih dari pada itu yaitu perubahan kecakapan, kebiasaan, sikap, pengertian, penghargaan, minat, penyesuaian diri, dan lain-lain yang berhubungan dengan pribadi seseorang.

Pelaksanaan belajar tidak selalu lancar dan berhasil dengan baik. Terkadang dalam proses belajar yang tidak lancar itu diakibatkan karena 
adanya hambatan atau kesulitan mahasiswa dalam belajar. Secara umum kesulitan belajar yang dihadapi mahasiswa terjadi pada mata kuliah bahasa asing atau yang bersifat hitung-hitungan. Hal ini juga terjadi pada mata kuliah bahasa Pali. Dilihat dari pemantauan dosen, terdapat mahasiswa yang kesulitan mengerjakan soal-soal bahasa Pali pada saat kuis, UTS atau UAS.

Berdasarkan pengamatan, ketika mahasiswa diberikan penjelasan dan diberikan soal latihan, dapat dikerjakan dengan baik, namun pada saat pengambilan nilai, mahasiswa merasa kesulitan. Hal tersebut bisa dilihat dari hasil belajar dalam bentuk skor (angka) yang kurang memuaskan. Ketika UTS semester ganjil untuk mata kuliah bahasa Pali, di beberapa kelas memperoleh nilai tidak memuaskan. Dilihat dari kriteria ketuntasan belajar dengan grade minimal C dengan nilai angka antara 60,00-64,99, maka nilai di bawah angka 60,00 belum tuntas.

Dari hasil UTS Semester V Dharmacarya, terdapat 5 mahasiswa memperoleh nilai di bawah 60 sehingga dinyatakan hasil UTS tersebut belum tuntas. Semester III Dharmacarya terdapat 3 mahasiswa yang memperoleh nilai tidak tuntas. Semester III Dharmaduta terdapat 5 mahasiswa yang tidak tuntas. Sedangkan Semester I Dharmaduta terdapat 6 mahasiswa yang tidak tuntas.

Bahasa Pali merupakan bahasa kitab suci agama Buddha yang perlu dilestarikan. Meskipun diketahui mempelajari bahasa Pali memiliki tingkat keasulitan yang cukup tinggi dikarenakan tata bahasa yang relatif rumit. Mempelajari bahasa Pali membutuhkan perhatian penuh dan keuletan agar dapat memahami dengan maksimal. Bahasa Pali sebenarnya dapat diterapkan dalam kehidupam sehari-hari bagi yang benar-benar telah menguasai tata bahasa dan hafal kosakata dalam bahasa Pali.

Berdasarkan uraian di atas, penulis tertarik untuk mengetahui penyebab kesulitan yang dihadapi oleh mahasiswa dalam mengerjakan soal-soal UTS mata kuliah bahasa Pali pada tiga aspek menulis, tata bahasa, dan kosakata. Identifikasi kesulitan tersebut penulis lakukan dengan melakukan penelitian dengan judul “Diagnosis Kesulitan Belajar Mata Kuliah Bahasa Pali pada Mahasiswa STABN Sriwijaya Tangerang Banten".

\section{Diagnosis Kesulitan Belajar}

Istilah diagnosis biasa digunakan dalam bidang medis. Menurut Thorndike dan Hagen (Arifin, 2017: 307), diagnosis diartikan sebagai: Upaya atau proses menemukan kelemahan atau penyakit (weakness, disease) yang dialami seseorang melalui pengujian dan studi yang seksama mengenai gejalagejalanya (symtoms); studi yang seksama terhadap fakta tentang suatu hal untuk menemukan karakteristik atau kesalahan-kesalahan dan sebagainya yang esensial; dan keputusan yang dicapai setelah dilakukan suatu studi yang seksama atas gejala-gejala atau fakta-fakta tentang suatu hal. Dijelaskan pula oleh Ebekunt (2009: 5) bahwa diagnosis adalah cara menemukan sebab-sebab kelemahan dengan pengamatan. 
Dari pengertian tersebut di atas dapat disimpulkan bahwa diagnosis bukan hanya sekadar mengidentifikasi jenis, karakteristik maupun latar belakang dari suatu kelemahan atau penyakit tertentu, melainkan juga mengimplikasikan suatu upaya untuk meramalkan kemungkinan dan menyarankan tindakan pemecahannya. Namun dalam penelitian ini, hanya akan dibahas diagnosis belum mencakup prognosis. Penelitian lanjutan terhadap tindak lanjut berupa prognosis akan dilakukan berdasarkan hasil diagnosis dalam penelitian ini.

Skinner berpandangan bahwa belajar adalah suatu perilaku. Menurut Gagne belajar merupakan kegiatan yang kompleks. Piaget berpendapat bahwa pengetahuan dibentuk oleh individu, sebab individu melakukan interaksi terus menerus dengan lingkungan (Dimyati dan Mudjiono, 2015: 9-16).

Dari pendapat para ahli tersebut dapat dijelaskan bahwa belajar adalah suatu perilaku untuk mengondisikan interaksi secara terus menerus untuk membentuk individu sesuai dengan tujuan yang direncanakan. Kegiatan belajar tersebut dapat dialami oleh orang yang sedang belajar. Di samping itu kegiatan belajar juga dapat diamati oleh orang lain. Belajar bertujuan untuk mendapatkan beraneka macam pengetahuan, namun juga dilengkapi dengan keterampilan dan sikap yang diperoleh secara bertahap dan berkelanjutan.

Dalam proses belajar tidak selalu mengalami keberhasilan, bahkan tak jarang terjadi berbagai kendala atau kesulitan dalam berbagai aspek. Seorang mahasiswa mengalami kesulitan dalam belajar. Burton (1992: 622-624) mengidentifikasikan bahwa seorang mahasiswa dapat dianggap mengalami kesulitan belajar jika yang bersangkutan mengalami kegagalan (failure) tertentu dalam mencapai tujuan-tujuan belajarnya.

Dari penjelasan tersebut diketahui bahwa mahasiswa mengalami kegagalan dalam belajar apabila dalam batas waktu yang ditentukan tidak mencapai ukuran tingkat keberhasilan minimal dalam pelajaran tertentu seperti yang telah ditetapkan oleh dosen. Hal lain yang menjadi ciri bahwa mahasiswa dikatakan gagal apabila yang bersangkutan tidak dapat mencapai prestasi yang semestinya, sedangkan dalam prediksi hal tersebut dapat diraih dengan hasil yang memuaskan.

Menurut Burton dalam Abin S.M. (2002: 325-326), faktor-faktor yang menyebabkan kesulitan belajar individu dapat berupa faktor intern, yaitu yang berasal dari dalam diri yang bersangkutan, dan faktor ekstern, adalah faktor yang berasal dari luar diri yang bersangkutan. Penjelasan mengenai faktor tersebut akan dipaparkan selanjutnya.

Untuk melakukan kegiatan belajar pembelajar menghadapi masalah secara intern. Jika pembelajar tidak dapat mengatasi masalahnya, maka tidak dapat belajar dengan baik. Faktor intern yang dialami oleh pembelajar dalam proses belajar menurut Dimyati dan Mudjiono (2015: 239-253) adalah sebagai berikut: sikap terhadap belajar, motivasi belajar, konsentrasi belajar, mengolah bahan ajar dan intelegensi. Sedangkan faktor ekstern meliputi beberapa faktor 
meliputi guru sebagai pembina siswa belajar, sarana prasarana pembelajaran, dan kebijakan penilaian.

Dari berbagai faktor yang melatarbelakangi timbulnya kesulitan belajar mahasiswa yaitu faktor intern dan ekstern. Faktor intern berasal dari dalam diri individu atau mahasiswa itu sendiri. Faktor intern ini seperti: inteligensi, minat belajar, kesehatan, dan gizi mahasiswa. Faktor ekstern berasal dari luar diri individu seperti lingkungan keluarga, bahan ajar, lingkungan sekolah, lingkungan tempat tinggal, teman sebaya, serta fasilitas belajar baik di sekolah maupun di rumah.

Dengan mengaitkan kedua pengertian di atas dapat didefinisikan diagnosis kesulitan belajar sebagai suatu proses upaya untuk memahami jenis dan karakteristik serta latar belakang kesulitan-kesulitan belajar dengan menghimpun berbagai informasi selengkap mungkin sehingga mempermudah dalam pengambilan kesimpulan guna mencari alternatif kemungkinan pemecahannya.

Langkah operasional diagnosis kesulitan belajar menurut (Hamdayama, 2016: 97) dilakukan dengan dua metode yaitu metode criterion referenced dan metode norm-references. Metode criterion referenced, maksudnya tes yang mengasumsikan bahwa instrumen evaluasi atau soal yang digunakan telah dikembangkan dengan memenuhi syarat-syarat tertentu. Metode normreferences, maksudnya nilai prestasi rata-rata dijadikan ukuran pembanding bagi setiap nilai prestasi individu masing-masing siswa.

\section{Bahasa Pali}

Bahasa Pali merupakan bahasa yang digunakan dalam penulisan Kitab Suci Tipitaka. Sehingga Bahasa Pali ini bukan merupakan bahasa percakapan sehari-hari. Tidak berbeda jauh dengan bahasa Pali adalah bahasa Sansekerta, yang memiliki aksara tersendiri dan pemakaiannya sangat luas. Dapat ditemukan aneka bentuk tulisan dalam bahasa Sansekerta seperti karya sastra, seni ataupun agama.

Mempelajari suatu bahasa menjadi lebih mudah jika bisa dipraktikkan langsung dalam percakapan. Tetapi begitu sulit menggunakan bahasa Pali sebagai bahasa percakapan sehari-hari. Namun demikian, apabila banyak membaca naskah berbahasa Pali maka akan semakin banyak memiliki perbendaharaan kata. Berdasarkan abjadnya, bahasa Pali memiliki jenis lebih banyak dibandingkan dengan bahasa lain. Dalam bahasa Pali terdapat 41 abjad/huruf yang terdiri atas 8 vokal dan 33 konsonan. Dari 41 huruf ini, diucapkan dengan cara yang berbeda-beda, yaitu: cara mengucapkan guttural, palatal, cerebral, dental dan labial (Cunda, 2010: 3-10).

Aspek penilaian dalam mata kuliah bahasa Indonesia meliputi aspek berbicara, mendengar, membaca dan menulis. Sedangkan dalam mata kuliah bahasa Pali aspek yang dinilai meliputi berbicara, tata bahasa (proses deklinasi), penulisan (lambang dalam bahasa Pali) dan kosakata (pengetahuan). Aspek berbicara yang dinilai dalam bahasa Pali menilai 
pengucapan kosakata di mana dalam tulisannya terdapat tanda baca yang memengaruhi cara membaca suatu kata.

Dalam penelitian ini aspek penilaian yang diambil terdiri dari tiga aspek yaitu tata bahasa, penulisan dan kosakata. Penilaian ini dilakukan dalam kegiatan UTS. Dalam tiga aspek ini dilihat mahasiswa mengalami kendala, terbukti dengan nilai UTS yang masih belum memuaskan.

\section{Penelitian Relevan}

Diagnosis kesulitan belajar adalah pemeriksaan terhadap keadaan yang sulit dalam usaha memperoleh kepandaian ilmu. Dalam hal ini diagnosis kesulitan belajar yang dimaksud adalah menemukan faktor kesulitan belajar Bahasa Pali pada mahasiswa STABN Sriwijaya Tangerang Banten. Terdapat penelitian terdahulu yang dapat dijadikan acuan dalam melakukan acuan ini. Penelitian pertama dilakukan oleh Hanifah Nurul Husnulifah pada tahun 2008/2009 tentang "Faktor kesulitan belajar bahasa Arab di SMP Islam Pedomasan Jombang Tahun Ajaran 2008/2009 dan penulis mendapatkan penguatan dari karya tulis Endang Rusyani pada tahun 2008 tentang Diagnosis Kesulitan Belajar Bahasa.

\section{B. Metodologi}

Metode yang digunakan dalam penelitian ini adalah survey dengan jenis deskriptif kuantitatif. Sugiyono (2013: 24) mengemukakan bahwa metode penelitian survei merupakan metode penelitian kuantitatif yang digunakan untuk mendapatkan data yang terjadi pada masa lampau atau saat ini, tentang keyakinan, pendapat, karakteristik, perilaku, hubungan variabel dan untuk menguji beberapa hipotesis tentang variabel sosiologis dan psikologis dari sampel yang diambil dari populasi tertentu. Teknik pengumpulan data dengan pengamatan yaitu melalui kuesioner dan hasil penelitian cenderung untuk digeneralisasikan.

\section{Hasil dan Pembahasan}

Dalam penelitian ini data diperoleh dengan non-tes yaitu dengan cara penyebaran angket kepada responden dan dengan tes melalui penyelesaian soal UTS oleh responden yang berjumlah 49 orang. Angket dengan variabel tunggal yaitu diagnosis kesulitan belajar mata kuliah bahasa Pali pada mahasiswa STABN Sriwijaya berisi 41 butir instrumen. Data yang diperoleh kemudian dideskripsikan dalam dua tahap yaitu data penelitian secara keseluruhan dan deskripsi data per faktor diagnosis kesulitan belajar serta deskripsi data diagnosis kesulitan belajar dari aspek bahasa. 
Tabel 1 Statistik Deskriptif

\begin{tabular}{|l|l|l|l|}
\hline & \multicolumn{1}{|c|}{ Skor } & $\begin{array}{c}\text { Diagnosis kesulitan } \\
\text { belajar dari faktor } \\
\text { intern }\end{array}$ & $\begin{array}{c}\text { Diagnosis kesulitan } \\
\text { belajar dari faktor } \\
\text { ekstern }\end{array}$ \\
\hline $\mathrm{N}$ & 49 & 49 & 49 \\
\hline Minimum & 106 & 54 & 51 \\
\hline Maximum & 129 & 68 & 62 \\
\hline Mean & 118 & 61 & 56 \\
\hline Standar Deviasi & 11 & 7 & 5 \\
\hline
\end{tabular}

Berikut keterangan output statistik dari tabel di atas :

a) $\mathrm{N}$ menunjukkan jumlah data berjumlah 49 buah data

b) Mean menunjukkan rata-rata nilai kuisioner diagnosis kesulitan belajar mata kuliah bahasa Pali pada mahasiswa STABN Sriwijaya sebesar 118.

c) Standar deviasi diagnosis kesulitan belajar mata kuliah bahasa Pali pada mahasiswa STABN Sriwijaya yaitu 11 .

d) Minimum menunjukkan data terkecil dari diagnosis kesulitan belajar mata kuliah bahasa Pali pada mahasiswa STABN Sriwijaya yaitu 106.

e) Maksimum menunjukkan data terbesar dari diagnosis kesulitan belajar mata kuliah bahasa Pali pada mahasiswa STABN Sriwijaya yaitu 129.

Deskripsi data diagnosis aspek bahasa yang diperoleh dari hasil menyelesaikan soal UTS semester Ganjil, sebagai berikut :

Tabel 2 Aspek Kesulitan Belajar

\begin{tabular}{|c|c|c|c|c|c|c|}
\hline \multirow{3}{*}{$\begin{array}{l}\text { No. } \\
\text { Soal }\end{array}$} & \multicolumn{6}{|c|}{ Aspek Soal } \\
\hline & \multicolumn{2}{|c|}{ Tata Bahasa } & \multicolumn{2}{|c|}{ Penulisan } & \multicolumn{2}{|c|}{ Kosakata } \\
\hline & Benar & Salah & Benar & Salah & Benar & Salah \\
\hline 1. & 27 & 22 & & & & \\
\hline 2. & & & & & 25 & 24 \\
\hline 3. & 28 & 21 & & & & \\
\hline 4. & & & 23 & 26 & & \\
\hline 5. & 25 & 24 & & & & \\
\hline 6. & 27 & 22 & & & & \\
\hline 7. & & & & & 27 & 22 \\
\hline 8. & 25 & 24 & & & & \\
\hline 9. & 28 & 21 & & & & \\
\hline 10. & & & 21 & 28 & & \\
\hline 11. & & & & & 9 & 40 \\
\hline 12. & & & 24 & 25 & & \\
\hline 13. & & & 9 & 40 & & \\
\hline 14. & & & & & 9 & 40 \\
\hline 15. & & & 4 & 45 & & \\
\hline 16. & 5 & 44 & & & & \\
\hline 17. & & & & & 6 & 43 \\
\hline
\end{tabular}




\begin{tabular}{|c|c|c|c|c|c|c|}
\hline \multirow{2}{*}{$\begin{array}{c}\text { No. } \\
\text { Soal }\end{array}$} & \multicolumn{6}{|c|}{ Aspek Soal } \\
\cline { 2 - 7 } & \multicolumn{2}{|c|}{ Tata Bahasa } & \multicolumn{2}{c|}{ Penulisan } & \multicolumn{2}{c|}{ Kosakata } \\
\cline { 2 - 7 } & Benar & Salah & Benar & Salah & Benar & Salah \\
\hline 18. & & & & & 5 & 44 \\
\hline 19. & & & 5 & 44 & & 49 \\
\hline 20. & & & & & 0 & \\
\hline 21. & & & 0 & 49 & & 262 \\
\hline & 165 & 178 & 86 & 208 & 81 & \\
\hline
\end{tabular}

Dari hasil analisis data berupa tes yang berjumlah 21 soal dengan aspek tata bahasa, menulis dan kosakata, yang memiliki tingkat kesalahan terkecil adalah pada aspek tata bahasa sebesar 178 dan tingkat kesalahan terbesar pada aspek kosakata sebesar 262. Artinya dalam aspek tata bahasa mahasiswa dapat memahami dengan baik, sehingga hanya sebagian kecil mahasiswa yang mengalami kesulitan dalam aspek ini. Sedangkan dalam aspek kosakata tingkat kesulitan yang dialami oleh mahasiswa mendapat poin terbesar. Tidak dipungkiri bahwa dalam aspek kosakata bahasa Pali, memiliki tingkat kerumitan yang cukup tinggi dalam hal penulisan tanda baca, dan artinya untuk dihafalkan dalam persiapan kuis, UTS dan UAS.

1. Deskripsi Data secara Keseluruhan tentang Diagnosis Kesulitan Belajar

Data yang diperoleh dari pengisian kuesioner sebagai skor mentah selanjutnya dikonversi atau diubah menjadi nilai standar. Dalam penelitian yang dilakukan ini menggunakan nilai standar berskala tiga. Dijelaskan oleh Sudijono (2009: 328-329) tentang cara melakukan standarisasi nilai. Dalam melakukan standarisasi nilai ini terlebih dahulu didapatkan rata-rata hitung $($ Mean $/ \mathrm{M})$ dan standar deviasi (SD) dari data yang diperoleh tersebut.

Dengan demikian untuk nilai keseluruhan dari diagnosis kesulitan belajar mata kuliah bahasa Pali pada mahasiswa STABN Sriwijaya dapat dijelaskan dalam distribusi frekuiensi sebagaimana tercantum pada tabel berikut ini:

Tabel 3 Distribusi Nilai Diagnosis Kesulitan Belajar

\begin{tabular}{|c|c|c|c|c|}
\hline No. & Interval & Kriteria & Frekuensi & Persentase \\
\hline 1 & $\geq 129$ & Tinggi & 7 & $14,29 \%$ \\
\hline 2 & $106-128$ & Sedang & 35 & $71,42 \%$ \\
\hline 3 & $<106$ & Rendah & 7 & $14,29 \%$ \\
\hline & Jumlah & & 49 & $100 \%$ \\
\hline
\end{tabular}

Tabel distribusi nilai diagnosis kesulitan belajar menunjukkan bahwa bagian terbesar mahasiswa mendapatkan nilai sedang yaitu sebesar 71,42\%, artinya kelompok ini didiagnosis memiliki kesulitan belajar dalam tingkat sedang terhadap mata kuliah bahasa Pali. Sedangkan bagian terkecil mendapatkan nilai tinggi dan rendah masing-masing sebanyak $14,29 \%$ artinya kelompok ini didiagnosis memiliki kesulitan belajar yang tinggi terhadap 
mata kuliah bahasa Pali dan kelompok yang didiagnosis memiliki kesulitan belajar rendah terhadap mata kuliah bahasa Pali.

2. Deskripsi Data per Faktor Penelitian

Pada penelitian ini, penulis mengelompokkan skor yang diperoleh secara keseluruhan ke dalam dua kelompok besar yaitu dimensi kesulitan belajar faktor intern dan dimensi kesulitan belajar faktor ekstern. Selain itu terdapat satu dimensi pendukung data yaitu melalui dimensi aspek bahasa itu sendiri.

a. Dimensi Diagnosis Kesulitan Belajar Faktor Intern

Data yang diperoleh peneliti dalam dimensi diagnosis faktor intern sebagai skor mentah selanjutnya dikonversi atau diubah ke dalam nilai standar, dengan hasil sebagai berikut:

Tabel 4 Distribusi Nilai Diagnosis Kesulitan Belajar Faktor Intern

\begin{tabular}{|c|c|c|c|c|}
\hline No. & Interval & Kriteria & Frekuensi & Persentase \\
\hline 1. & $\geq 68$ & Tinggi & 5 & $10 \%$ \\
\hline 2. & $54-67$ & Sedang & 37 & $76 \%$ \\
\hline 3. & $<54$ & Rendah & 7 & $14 \%$ \\
\hline & Jumlah & & 49 & $100 \%$ \\
\hline
\end{tabular}

b. Dimensi Diagnosis Kesulitan Belajar Faktor Ekstern

Data yang diperoleh peneliti dalam dimensi diagnosis faktor ekstern sebagai skor mentah selanjutnya dikonversi atau diubah ke dalam nilai standar, dengan hasil sebagai berikut :

Tabel 5 Distribusi Nilai Diagnosis Kesulitan Belajar Faktor Ekstern

\begin{tabular}{|c|c|c|c|c|}
\hline No. & Interval & Kriteria & Frekuensi & Persentase \\
\hline 1. & $\geq 62$ & Tinggi & 9 & $18,37 \%$ \\
\hline 2. & $51-61$ & Sedang & 35 & $71,43 \%$ \\
\hline 3. & $<51$ & Rendah & 5 & $10,2 \%$ \\
\hline & Jumlah & & 49 & $100 \%$ \\
\hline
\end{tabular}

c. Dimensi Diagnosis Kesulitan Belajar Aspek Bahasa

Data yang diperoleh peneliti dalam dimensi diagnosis aspek bahasa sebagai skor mentah selanjutnya dikonversi atau diubah ke dalam nilai standar, dengan hasil sebagai berikut:

Tabel 6 Distribusi Nilai Diagnosis Kesulitan Belajar Aspek Bahasa

\begin{tabular}{|c|c|c|c|}
\hline No. & Aspek & Frekuensi & Persentase \\
\hline 1. & Tata Bahasa & 178 & $28 \%$ \\
\hline 2. & Menulis & 208 & $32 \%$ \\
\hline 3. & Kosakata & 262 & $40 \%$ \\
\hline & Jumlah & 648 & $100 \%$ \\
\hline
\end{tabular}




\section{Simpulan}

Berbagai tahapan dalam penelitian ini telah dilalui, mulai dari memaparkan latar belakang penelitian ini sampai dengan pemaparan hasil penelitian. Untuk selanjutnya peneliti akan menyimpulkan hasil penelitian tentang diagnosis kesulitan belajar mata kuliah bahasa Pali pada mahasiswa STABN Sriwijaya Tangerang Banten, sebagai berikut :

1. Diagnosis kesulitan belajar mata kuliah bahasa Pali pada mahasiswa STABN Sriwijaya Tangerang Banten sebesar 71,42\% dengan kategori sedang dan dilihat dari aspek bahasa diketahui perolehan persentase terbesar $40 \%$ pada aspek kosakata, artinya dilihat dari aspek bahasa, mahasiswa mengalami kesulitan yang cukup signifikan besar dalam hal kosakata, di antaranya dalam menghafal kosakata tersebut.

2. Terdapat dua kelompok besar yang menjadi faktor kesulitan belajar mahasiswa yaitu faktor intern dan faktor ekstern. Faktor intern kesulitan belajar mata kuliah bahasa Pali berasal dari dalam diri mahasiswa itu sendiri memiliki persentase lebih besar dibandingkan faktor ekstern yang merupakan faktor yang berasal dari luar diri mahasiswa itu sendiri. Selain itu diklasifikasikan terdiri diri faktor yang berpengaruh terhadap kesulitan belajar yang berasal dari aspek bahasa tersebut, yaitu tata bahasa, penulisan dan kosakata. Dengan demikian dapat diketahui bagian yang menjadi kesulitan belajar mahasiswa dari sisi bahasa.

Dengan adanya hasil penelitian ini, sebagaimana telah disimpulkan di atas, maka peneliti akan mengemukakan beberapa saran sebagai berikut:

a. Bagi para mahasiswa, dengan mengetahui hasil penelitian ini hendaknya lebih memaksimalkan kemampuan yang dimiliki, karena setiap individu memiliki kompetensi yang berbeda-beda.

b. Bagi institusi, dengan adanya hasil penelitian ini akan dapat mendorong institusi untuk mengagendakan kegiatan yang berhubungan dengan bahasa Pali dengan mendatangkan tenaga ahli yang dapat memotivasi mahasiswa dan memotivasi pelestarian bahasa Pali sebagai bahasa kitab suci.

c. Bagi peneliti lain, dengan adanya keterbatasan dalam penelitian ini, diharapkan peneliti lain mengadakan penelitian sejenis lebih lanjut dengan mengambil wilayah penelitian yang lebih luas, dan selanjutnya akan dapat menemukan solusi untuk mengatasi kesulitan yang dihadapi. 


\section{Daftar Pustaka}

Abin S.M.2002.Proses Belajar. Tangerang:PT. Pustaka Mandiri

Dimyati \& Mudjiono.2015. Belajar dan Pembelajaran. Jakarta: PT.Rineka Cipta

Etty Kartikawati dan Willem Lusikooy. 1994. Materi Pokok; Profesi Keguruan PGSM3904/2SKS Modul 1-6. Jakarta: Universitas Terbuka, Depdikbud.

Hamdayama, jumanta.2016. Metodologi pengajaran. Jakarta: Bumi aksara

http:/ / abudaud2010.blogspot.com. Minggu, 12 November 2017

http:/ / gebriellucifer.blogspot.com. Minggu, 12 November 2017

http:/ / ebekunt.wordpress.com. Minggu, 12 November 2017

http:/ / mutiaraendah.word press.com. Senin, 13 November 2017.

Sudijono, Anas.2009. Metode Penelitian Kuantitatif dan Kualitatif dan RED. Bandung:Alfabeta

Sukardi. 2004. Metodologi Penelitian Pendidikan. Jakarta:Bumi Aksara.

Supandi J Cunda.2010. Tata Bahasa Pali.Vidyavardhana Samuha

Surakhmad, Winarno.2004. Pengantar Interaksi Belajar Mengajar, Dasar dan Teknik Metodologi Pengajaran. Bandung: Tarsito

Usman, Husaini, \& Akbar, Purnomo Setiady. 2004. Metodologi Penelitian Sosial. Jakarta:Bumi Aksara. 